\title{
Experimental Thermal Analysis in Rotary Friction Welding of Dissimilar Materials
}

\author{
Eder Paduan Alves ${ }^{* 1}$, Rafael Cardoso Toledo², Francisco Piorino Neto¹, Fabio Gabarra Botter, Chen Ying An²
}

How to cite

Alves EP (D) https://orcid.org/0000-0002-8869-3168

Alves EP; Toledo RC; Piorino Neto F; Botter FG; An CY (2019) Experimental Thermal Analysis in Rotary Friction Welding of Dissimilar Materials. J Aerosp Technol Manag, 11: e4019. https://doi.org/10.5028/jatm.v11.1068

\begin{abstract}
Rotary friction welding process (RFW) is one of the most used processes in the world for manufacturing bimetallic components that require high mechanical strength. All process occurs in solid state at temperatures below the melting point of the involved materials, having as the main bonding mechanisms the diffusion and mechanical mixture. The purpose of this work was to carry out an experimental thermal analysis of the dissimilar joint AA6351 T6 aluminum and AISI 304L stainless steel during the friction welding operation through system of thermocouples. Gradients of temperature obtained had their data analyzed and recorded. Results of the experimental thermal analysis showed the behavior of the temperature in the bonding interface, how the dissipation occurs in the radial and longitudinal direction, heating rates, cooling, maximum temperatures reached, its relationship with the different stages of the process and the influence on mechanical properties of welded joint. This study is of great importance for relating the temperature distribution in the bonding interface with atomic diffusion and mechanical resistance of junction.
\end{abstract}

KEYWORDS: Friction welding, Temperature, Dissimilar materials, Thermocouples.

\section{INTRODUCTION}

The joining of materials with different physical and chemical properties on a permanent basis, with structural quality that meets design requirements for applications in aerospace, aviation, nuclear, military and automotive areas, has been a challenge for engineering in the last years. The rotary friction welding (RFW) process provides high productivity, repeatability and low cost. It produces dissimilar joints such as aluminum-stainless steel, aluminum titanium and copper-aluminum with great quality and mechanical properties better than the lowest resistance material used in the junction.

All heating responsible by the union is mechanically generated by friction between the parts to be welded. The friction between the surfaces enables a rapid increase in temperature in the bonding interface, causing the mass to deform plastically and to flow depending on the application pressure and centrifugal force creating a flash. This process causes the removal of impurities and oxides from the surfaces, promoting the creation of a surface with excellent physical and chemical adhesion (Alves et al. 2010). The temperature increase and constant application of pressure in the bonding interface for a determined time enables the atomic diffusion among the main elements of the two materials, and hence their union.

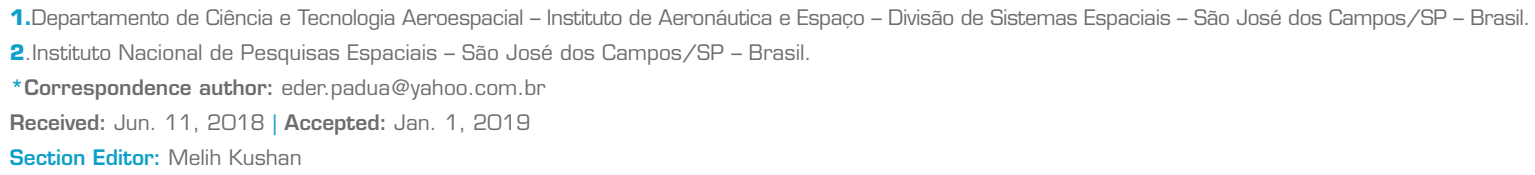


In friction welding of dissimilar materials, the temperature generated in the bonding interface is directly related with the weld strength and its interface properties. The non-uniform heat generation in the bonding interface generates the formation of intermetallic compounds, unbold zones, and insufficient plastic deformation to total removal of layers of oxides and other contaminants in the bonding interface. High temperature increases the intermetallic compound forming and, consequently, the thickness of intermetallic layer that affects the heat affected zone (HAZ) (Khan 2011).

Due to the relevance of the topic, there are many experimental and analytical studies published by researchers from different parts of the world: Wei and Sun (2018), Dawood et al. (2017), Ratkovic et al. (2017), Rombault (2011), Aritoshi and Okita (2003), Khan (2011), Kuchuk-Yatsenko and Zyakhor (2002), Basher (2013), Yilbas and Sahin (2014), Fukumoto et al. (2010), Nikolaev and Olshansky (1977), Seli et al. (2010), Maldonado-Zepeda (2001), Cenk et al. (2012), Moarrefzadeh (2012), Faizal et al. (2014), Li et al. (2012), Ruma et al. (2013), Singla (2010), Kimura et al. (2010) and Bouarroudj et al. (2017), Burakowiski and Wierzchon (1998).

Experimental analysis of temperature on bonding interface is of fundamental importance to the knowledge and understanding of the phenomena occurring in the formation of dissimilar joint obtained by RFW. Analytical calculations carried out until the time to temperature modeling are complex and do not allow obtaining precise values due to the large number of variables involved.

\section{ROTARY FRICTION WELDING PROCESS}

The process of friction welding is classified by the American Welding Society (AWS) as a solid state joining process in which bonding is produced at temperatures lower than the melting point of the base materials (Maldonado-Zepeda 2001). In the rotary friction welding, one of the pieces is fixed and submitted to a particular rotation by a motor drive (RPM), and the other is positioned, aligned and powered by a hydraulic piston up to touch the part in rotation. After this, P1 pressure is applied by a certain time ( $\mathrm{t} 1$ ), followed by the braking of rotation $(\mathrm{RPM}=0)$ and subsequent application of $\mathrm{P} 2$ for a time $\mathrm{t} 2$, finishing the welding. The main stages of the process can be observed in Fig. 1 (Alves 2016).

(a)

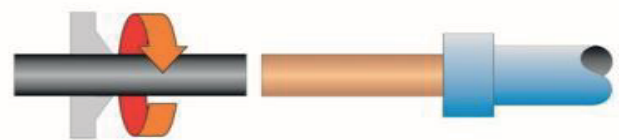

(b)

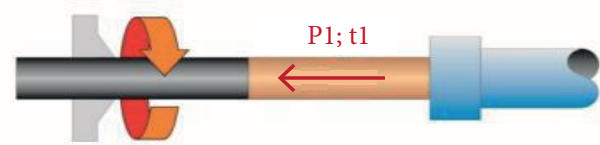

(c)

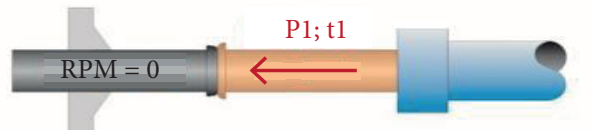

(d)

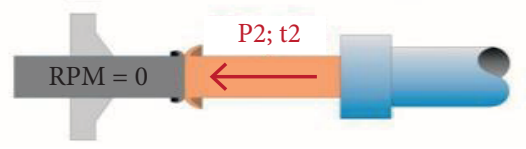

Figure 1. (a) Period of approximation; (b) P1, t1 application; (c) End of P1, t1 application and braking of machine (RPM = O); (d) P2, t2 application and finishing welding.

\section{FRICTION WELDING EQUIPMENT}

Dissimilar welded joints samples were carried out using a rotary friction welding machine, mark GATWICK, with relative speed (RPM) $3200 \mathrm{RPM}$, fixed pressure (P1 = $300 \mathrm{MPa}$; $2=1200 \mathrm{MPa})$, time ( $\mathrm{t} 1=5 \mathrm{~s} ; \mathrm{t} 2=2 \mathrm{~s})$, and constant piston displacement 
speed. These parameters used for the trials were obtained previously in a study conducted by Alves (2016), whose results have confirmed the rupture away from the bonding interface in AA 6351-T6 aluminum alloy. The materials were placed as shown in Fig. 2.

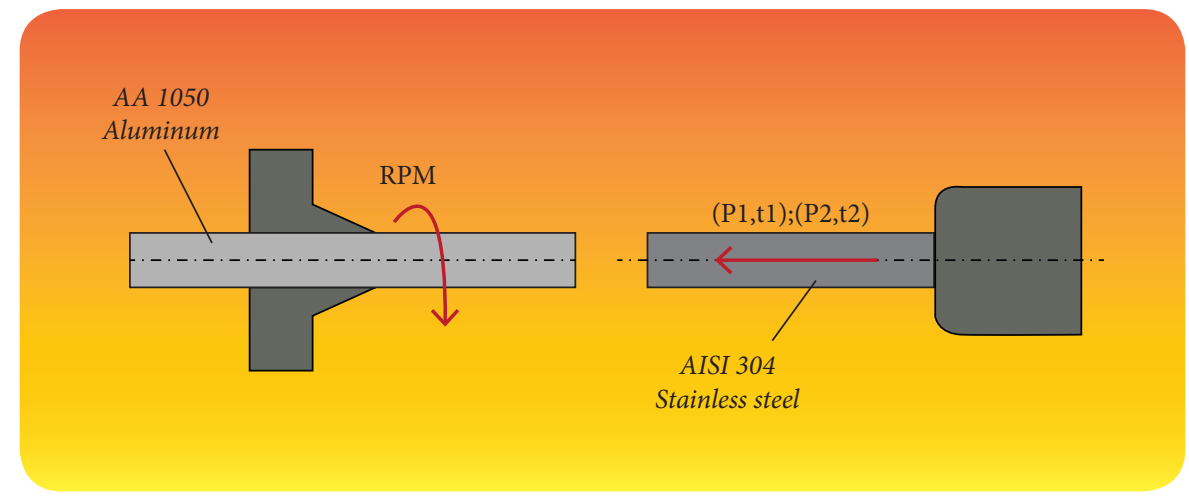

Figure 2. Schematic view of the materials placed before welding.

\section{MATERIALS AND METHODS}

Cylindrical pins used in this work were machined in conventional lathe with $14.8 \mathrm{~mm}$ diameter and $100 \mathrm{~mm}$ length (AISI $304 \mathrm{~L}$ stainless steel) and $110 \mathrm{~mm}$ (AA 6351-T6 alloy) with $3.2 \mu \mathrm{m}$ surface roughness, value obtained with the use of common tools for the machining process. Aluminum pins were manufactured with two different geometries in one of its ends, regular geometry and conical geometry (Fig. 3). Tables 1 and 2 present chemical compositions and mechanical properties of the materials.

Table 1. Nominal chemical compositions of materials.

\begin{tabular}{|c|c|c|c|c|c|c|c|c|c|c|}
\hline Material & \multicolumn{9}{|c|}{ Elements (wt \%) } \\
\hline $\begin{array}{c}\text { AA 6351-T6 } \\
\text { Aluminum }\end{array}$ & $\mathrm{Si}$ & $\mathrm{Fe}$ & $\mathrm{Cu}$ & $\mathrm{Mn}$ & $\mathrm{Mg}$ & $\mathrm{Cr}$ & $\mathrm{Zn}$ & $\mathrm{Ti}$ \\
\hline $\begin{array}{c}\text { AISI 304 L } \\
\text { Stainless steel }\end{array}$ & 0.96 & 0.22 & 0.02 & 0.46 & 0.58 & 0.005 & 0.006 & 0.02 & $\mathrm{Ni}$ \\
\hline
\end{tabular}

Table 2. Mechanical properties of materials used in present study.

\begin{tabular}{|l|c|c|c|}
\hline Base Material & Tensile Strength (MPa) & Yeld Strength (MPa) & Elongation [\%) \\
\hline AA 6351-T6 Aluminum & 323.68 & 297.25 & 14.0 \\
\hline AISI 304 L Stainless steel & 643.79 & 354.69 & 63.0 \\
\hline
\end{tabular}

Thermal analysis of the process was carried out by thermocouples used the MGC-PLUS system-HBM, model TG001D and thermocouples of type "J". To achieve the thermal testing it was manufactured pins in AISI 304L stainless steel with special holes for attachment of thermocouples in three different configurations (with four monitoring points): radial measurement; longitudinal measurement to $7.4 \mathrm{~mm}$ deep; and longitudinal measurement the $4.3 \mathrm{~mm}$ deep. All setting measurements were carried out in stainless steel pins (Fig. 3b). 
(a)

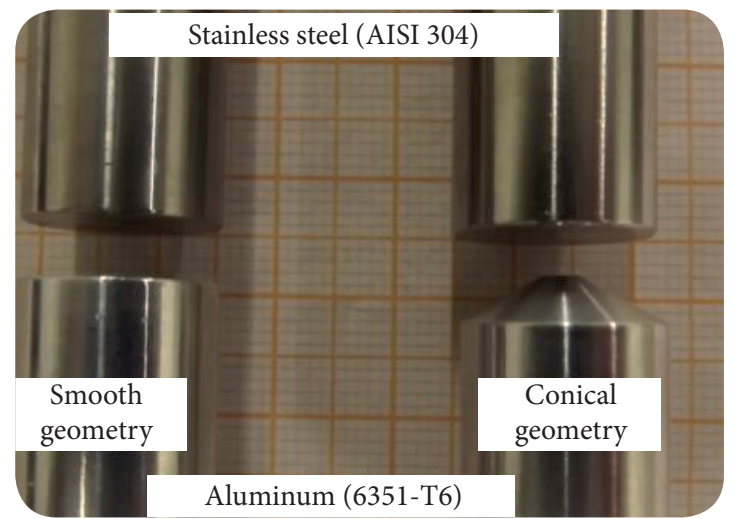

(b)

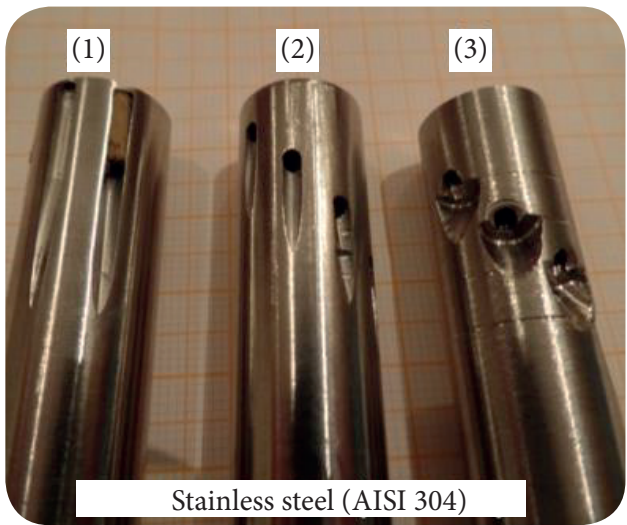

Figure 3. (a) Details of the aluminum pins geometry; (b) Steel pins with different holes for attachment of thermocouples.

\section{RESULTS AND DISCUSSION}

The analysis by thermocouples of dissimilar joints welded by RFW enabled a quantitative understanding of the process. There were performed 30 essays, being 15 for each sample type and parameters (P1, P2, t1 and t2) adopted were the resulting joints with higher resistance to traction. To eliminate and reduce the influence of external variables to the process, the tests were performed in a single day in sequence, under the same conditions. Figure 4 shows the equipment and thermocouples attached to the sample before and after welding.

(a)

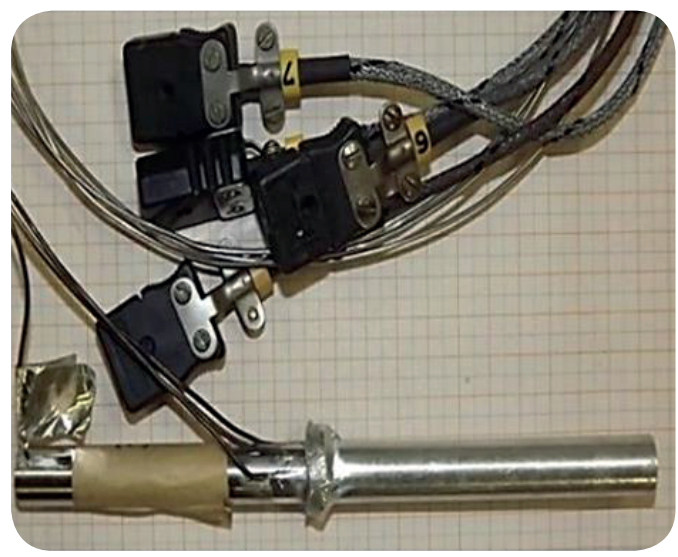

(b)

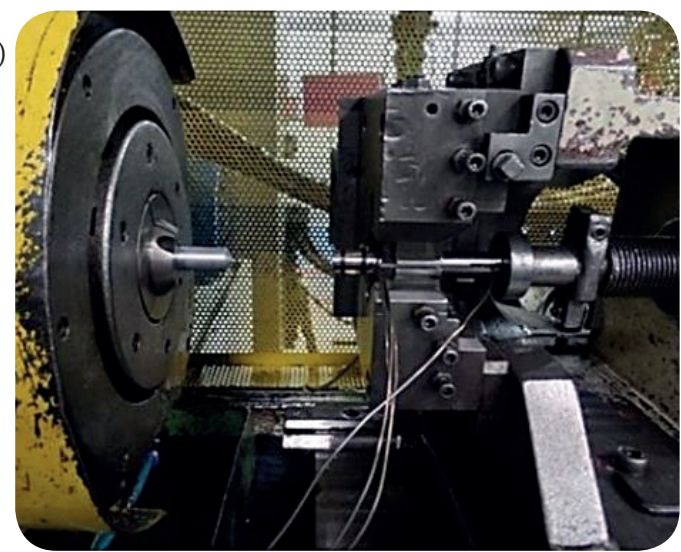

Figure 4. (a) Thermocouples fixed on the stainless steel pin after the welding finished;

(b) Welding equipment moments before performing the test.

\section{RADIAL TEMPERATURE PROFILE}

Friction welding tests for measuring the temperature variation in the radial direction used the setting of the thermocouples shown in Fig. 5. The thermocouple in position $0.0 \mathrm{~mm}$ is in the center of the pin, and the thermocouple in the $5.8 \mathrm{~mm}$ position lies in the region known as medium radius (higher temperature).

Figure 6a shows the radial temperature profile for welding with aluminum pins regular geometry, the highest temperature values found refer to the thermocouples attached to a distance of $5.8 \mathrm{~mm}$ from the centerline of the samples (medium radius). Figure $6 \mathrm{~b}$ shows the radial temperature profile for welding with aluminum pins with conical geometry, where higher temperature values were observed in the central region of the sample. 


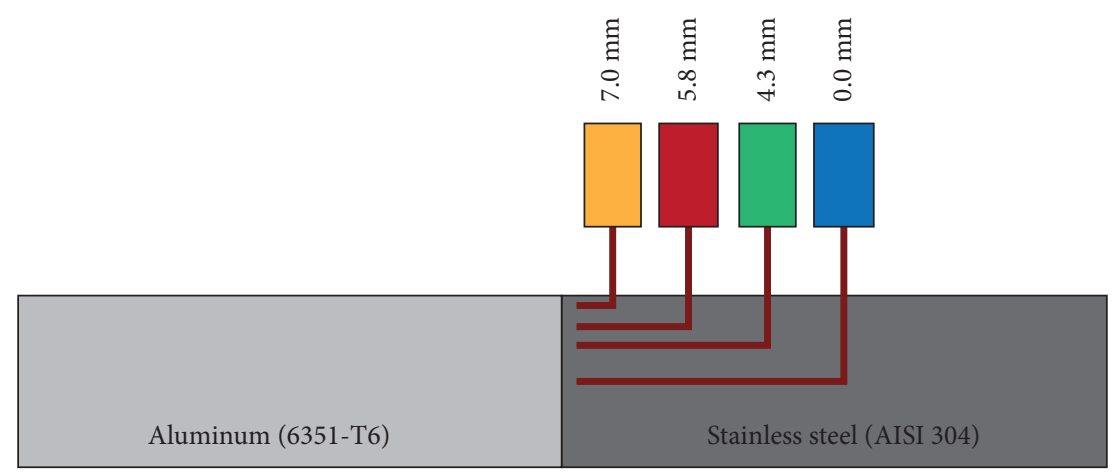

Figure 5. Configuration of the thermocouples for radial temperature profile.

(a)

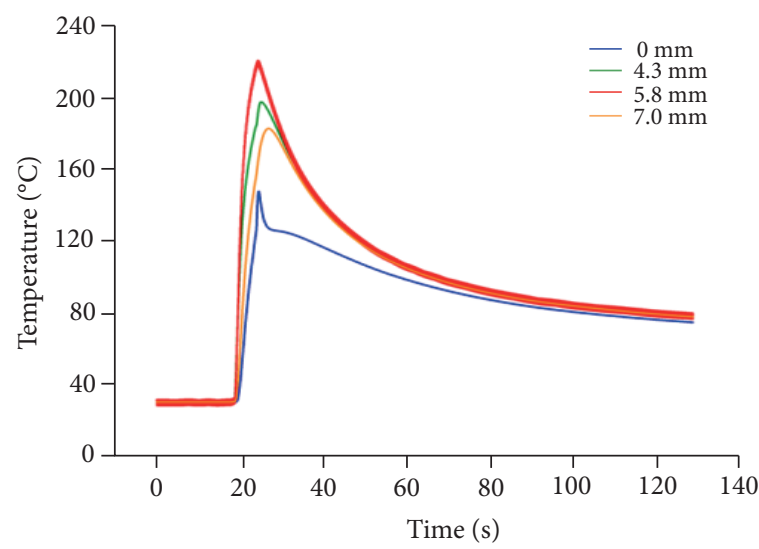

(b)

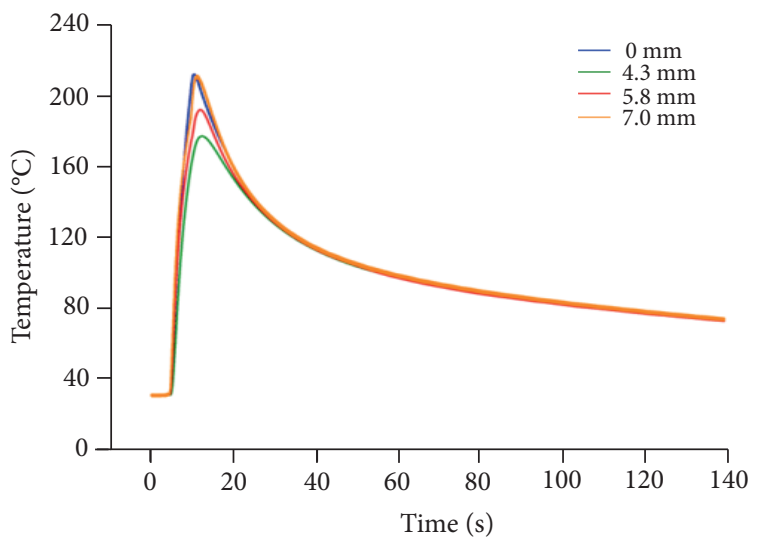

Figure 6. Radial temperature profile (a) aluminum pins with regular geometry;

(b) Aluminum pins with conical geometry.

Analyzing the graphics of $\mathrm{T} \times \mathrm{t}$, it was noted that in tests conducted with aluminum pins with conical geometry (Fig. 6b), the highest elevation in temperature occurred in the central region of the bonding interface since the start of the welding operation. Already in tests with aluminum pins with regular geometry (Fig 6a), the highest elevation in temperature occurred in the medium radius and then dissipated to other parts of the interface, which enables us to say that changing the geometry of pin from regular to conical caused the displacement of the region of highest temperature from the medium radius to the central region.

The conical geometry of the aluminum pin caused the heat flux at the bonding interface shift from the central region (higher temperature region) to the peripheral regions of the samples. This made possible a homogeneous diffusion in the contact surfaces, enabling better removal of layers of oxides and impurities present in these surfaces by plastic deformation.

\section{LONGITUDINAL TEMPERATURE PROFILE}

Figure 7 shows the thermocouple configuration used for testing of longitudinal profile with two different depths, $7.4 \mathrm{~mm}$ and $4.3 \mathrm{~mm}$, and with variable distances of bonding interface of 5, 10, 15, and $20 \mathrm{~mm}$.

Figures 8 and 9 present the longitudinal profiles of temperature with depths of fixing of thermocouples of $7.4 \mathrm{~mm}$ an $4.3 \mathrm{~mm}$, respectively. 


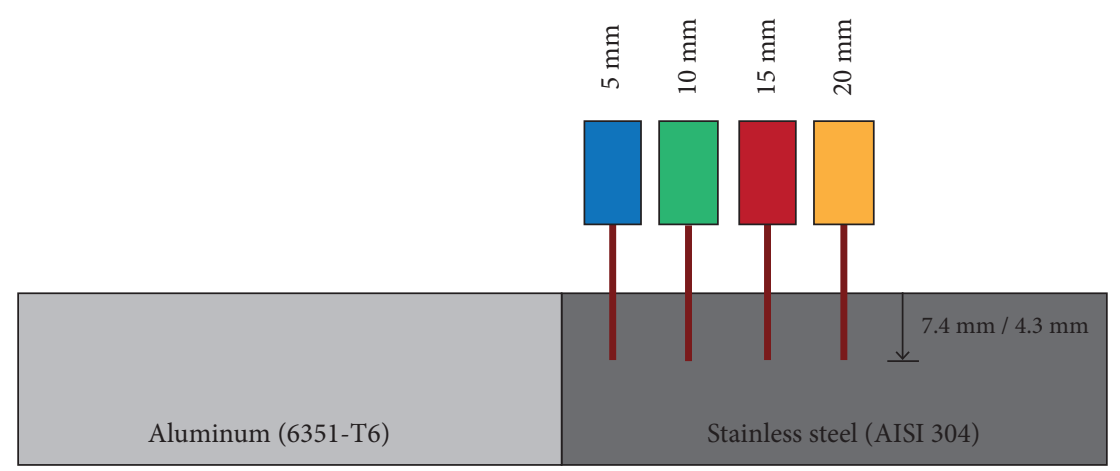

Figure 7. Configuration of the thermocouples for temperature longitudinal profile with depth of $7.4 \mathrm{~mm}$ and $4.3 \mathrm{~mm}$.

(a)

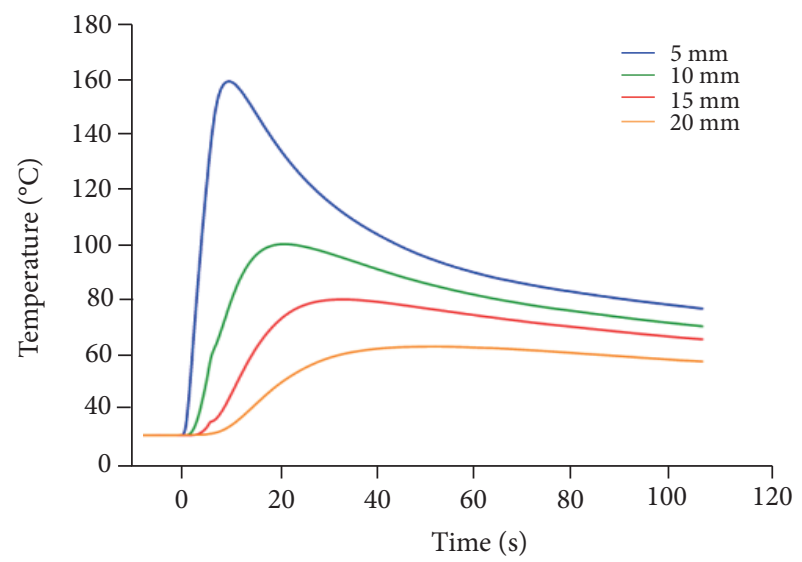

(b)

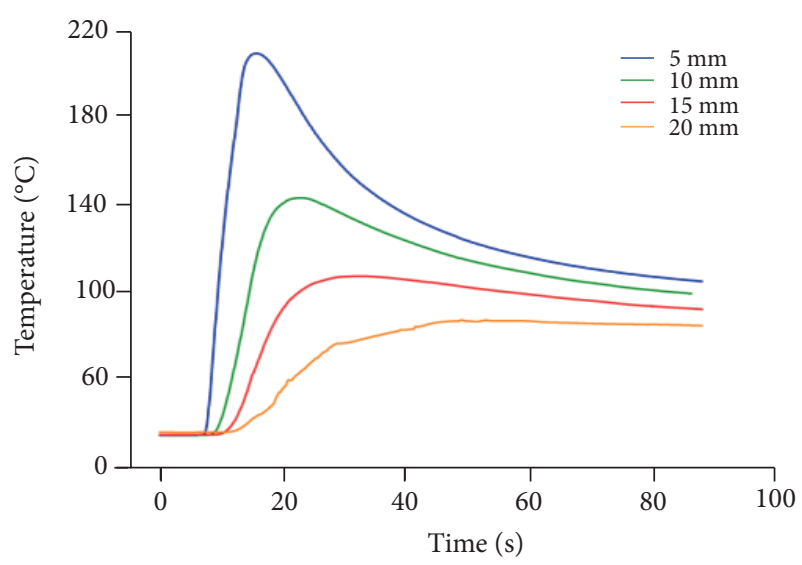

Figure 8. Temperature longitudinal profile with depth of fixing of $7.4 \mathrm{~mm}$ : (a) Aluminum pins with regular geometry; (b) Aluminum pins with conical geometry.

(a)

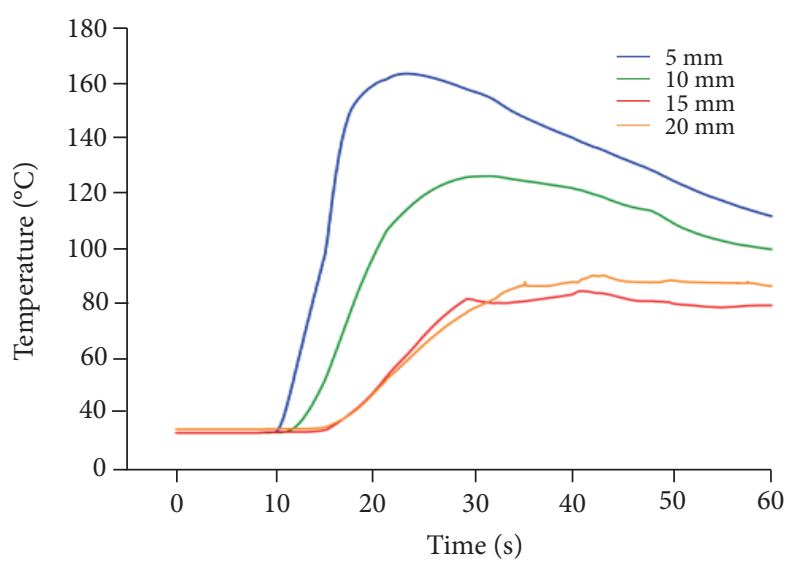

(b)

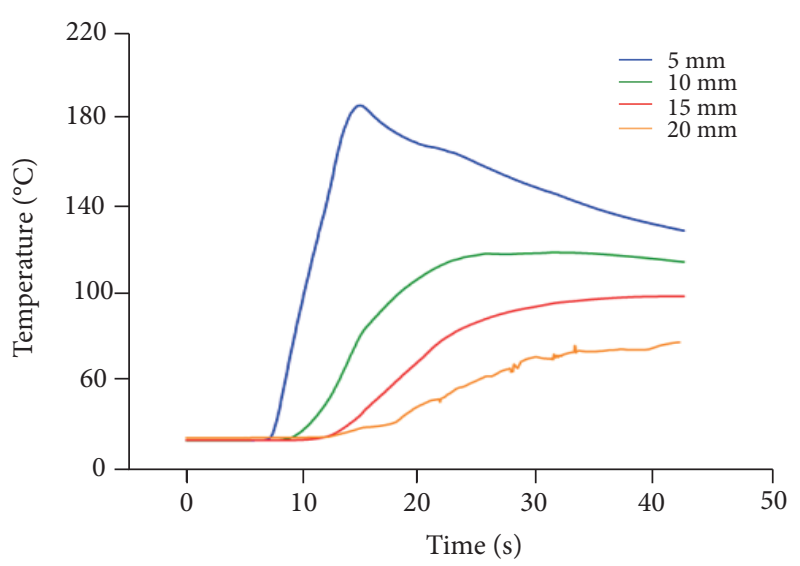

Figure 9. Temperature longitudinal profile with depth of fixing of $4.3 \mathrm{~mm}$ : (a) Aluminum pins with regular geometry; (b) Aluminum pins with conical geometry. 
The results of monitoring of the heat flux displacement in the longitudinal direction of the stainless steel pins with depths of $7.4 \mathrm{~mm}$ and $4.3 \mathrm{~mm}$ and different geometries of the aluminum pins showed similar curves. The highest temperature recorded was $210^{\circ} \mathrm{C}$ at a distance of $5.0 \mathrm{~mm}$ of bonding interface, sense of the length of the stainless steel with thermocouple fixed a depth of $7.4 \mathrm{~mm}$, using aluminum pin with conical geometry. During the welding operation, the aluminum pins with conical geometry have undergone a reduction in their length (LR), exceeding the pins with regular geometry.

Tension tests performed on samples considering the two aluminum cylindrical pin geometries showed that the use of cylindrical pin with conical geometry allowed an increase of mechanical resistance of the junction of $12 \%$ to $15 \%$. In the tension test number 2 (aluminum pins with conical geometry), the rupture occurred in the aluminum, away from the bonding interface. Table 3 shows the results of the tension tests.

Table 3. Results of tension tests carried out using aluminum cylindrical pins with regular and conical geometry.

\begin{tabular}{|c|c|c|c|c|c|c|}
\hline \multicolumn{7}{|c|}{ Aluminum pins with regular geometry } \\
\hline $\mathbf{N}^{\mathbf{0}}$ & P1 [MPa] & t1 [s] & $\mathrm{P} 2$ (MPa) & t2 [s] & LR $(\mathrm{mm}]$ & Tensile strenght [MPa] \\
\hline 1 & 300 & 5 & 1200 & 2 & 12 & 292 \\
\hline 2 & 300 & 5 & 1200 & 2 & 13 & 297 \\
\hline 3 & 300 & 5 & 1200 & 2 & 13 & 283 \\
\hline 4 & 300 & 7 & 1200 & 2 & 14 & 278 \\
\hline 5 & 300 & 7 & 1200 & 2 & 12 & 255 \\
\hline \multicolumn{7}{|c|}{ Aluminum pins with conical geometry } \\
\hline $\mathbf{N}^{\mathbf{0}}$ & P1 [MPa] & t1 [s] & $\mathrm{P2}$ [MPa] & t2 [s] & LR $(\mathrm{mm})$ & Tensile strenght (MPa] \\
\hline 1 & 300 & 5 & 1200 & 2 & 14 & 315 \\
\hline 2 & 300 & 5 & 1200 & 2 & 14 & 327 \\
\hline 3 & 300 & 5 & 1200 & 2 & 13 & 318 \\
\hline 4 & 300 & 7 & 1200 & 2 & 14 & 288 \\
\hline 5 & 300 & 7 & 1200 & 2 & 15 & 285 \\
\hline
\end{tabular}

Comparing the data obtained in this work with the referenced articles, we verify that the temperature is always cited as an important element in the system. Regardless of the dissimilar materials to be joined by RFW, if the cylindrical pin of lower mechanical strength presents conical tip geometry, it will provide better temperature distribution in the bonding interface, welds with good quality and great mechanical resistance.

\section{CONCLUSIONS}

Measurements and temperature monitoring with use of thermocouples are of extreme importance for analysis of the temperature distribution on the bonding interface seen its efficiency and large data collection capacity during friction welding. Tests conducted with two different pin geometries showed that the biggest rise in temperature occurs in the first three seconds of the process, independent of geometry. Pins with regular geometry have a higher temperature rise in the so-called medium radius away from the central region, while pins with conical geometry had the central region with highest elevation in temperature allowing better heat distribution in the bonding interface during welding.

The use of aluminum cylindrical pins with conical geometry in dissimilar joints involving aluminum alloys and stainless steel enables better temperature distribution on the surface of contact materials, favors activity of bonding mechanisms, generates a HAZ more homogeneous and increases mechanical resistance of the junction produced by friction welding process. 
Obtaining dissimilar joints where the rupture of the tension specimen occurs outside the bonding interface is a great indication that there was perfect distribution of temperature in the contact areas of the materials during the friction welding operation. When the rupture occurs in the bonding interface, usually the defects encountered are related to the poor distribution of temperature.

\section{AUTHORS' CONTRIBUTION}

All the authors contributed equally for the manuscript.

\section{FUNDING}

There are no funders to report for this submission.

\section{REFERENCES}

Alves EP (2016) Caracterização mecânica e estudo do perfil térmico na soldagem por fricção de materiais dissimilares (PhD Thesis). São José dos Campos: Instituto Nacional de Pesquisas Espaciais. In Portuguese.

Alves EP, Piorino Neto F, An CY (2010) Welding of AA1050 aluminum with AISI 304 stainless steel by rotary friction welding process. Journal of Aeroespace Technology and Management 2(3):301-306. https://doi.org/10.5028/jatm.2010.02037110

Aritoshi M, Okita K (2003) Friction welding of dissimilar metals. Welding International 17(4):271-275.

Basher UM (2013) Friction welding of 6061 aluminum alloy with YSZ-alumina composite for improved mechanical and thermal properties. (PhD Thesis). Penang: University Sains Malaysia.

Bouarroudj E, Chikh S, Abdi S, Miroud D (2017) Thermal analysis during a rotational friction welding. Journal of Applied Thermal Engineering 110:1543-1553. https://doi.org/10.1016/j.applthermaleng.2016.09.067

Burakowiski T, Wierzchon T (1998) Surface engineering of metals - principles, Equipment, Technologies. Boca Raton: CRC Press.

Dawood AB, Butt SI, Hussain G, Siddiqui MA, Maqsood A, Zhang F (2017) Thermal model of rotary friction welding for similar and dissimilar metals. Journal of Metals 7(6):224. https://doi.org/10.3390/met7060224

Faizal BA, Amarnath TS, Ninan RT (2014) An Investigation of Mechanical Properties of Aluminium 6063-T6 after Friction Welding Process. International Journal of Engineering Trends and Technology 17(5):203-207. https://doi.org/10.14445/22315381/IJETT-V17P241

Fukumoto S, Inoue T, Mizuno S, Okita K, Tomita T, Yamamoto A (2010) Friction welding of TiNi alloy to stainless steel using Ni interlayer. Science and Technology of Welding and Joining 15(2):124-130. https://doi.org/10.1179/136217109X12577814486692

Khan IA (2011) Experimental and numerical investigation on the friction welding process (PhD Thesis). Telengana: Jawaharlal Nehru Technological University.

Kimura M, Inoue H, Kusaka M, Kaizu K, Fuji A (2010) Analysis method of friction torque and weld interface temperature during friction process of steel friction welding. Journal of Solid Mechanics and Materials Engineering 4(3):401-413. https://doi.org/10.1299/ jmmp.4.401

Kuchuk-Yatsenko SI Zyakhor IVI (2002) Mechanism of bimetal joints formation in friction welding. The Paton Welding Journal 7:2-9.

Li W, Shi S, Wang F, Zhang Z, Ma T, Li J (2012) Numerical simulation of friction welding processes based on ABAQUS environment. Journal of Engineering Science and Technology Review 5(3):10-19.

Maldonado-Zepeda C (2001) The effect of interlayers on dissimilar friction weld properties (PhD Thesis). Toronto: University of Toronto.

Cenk M, Mumin S, Hilmi K (2012) Temperature determination of ST-Al joints during friction welding. Advanced Materials Research 463464:1538-1542. https://doi.org/10.4028/www.scientific.net/AMR.463-464.1538

Moarrefzadeh A (2012) Study of Heat Affected Zone (HAZ) in friction welding process. Journal of Mechanical Engineering 1(1):11-17.

Nikolaev G, Olshansky N (1977) Advanced welding process. Moscow: MIR Publishers. 
Ratkovic NR, Arsic DM, Lazic VN, Nikolic RR, Hadzima B, Palcek P, Sedmak AS (2017) Influence of friction welding parameters on properties of the Al-Cu Joint. FME Transactions 45(1):165-171. https://doi.org/10.5937/fmet1701165R

Rombault P (2011) Joining of dissimilar materials through rotary friction welding (Master's Thesis). Ghent: Ghent University.

Ruma, Wahed MA, Farhan M (2013) A study on the effect of external heating of the friction welded joint. International Journal of Emerging Technology and Advanced Engineering 3(5):603-613.

Seli H, Noh MZ, Ismail AIM, Rachman E, Ahmad ZA (2010) Characterization and thermal modelling of friction welded alumina-mild steel with the use of al 1100 interlayer. Journal of Alloys and Compounds 506(2):703-709. https://doi.org/10.1016/j.jallcom.2010.07.047

SINGLA YK (2010) Evaluation of mechanical behaviour of friction welded bimetallic welds (Master's Thesis). Patiala: University Patiala.

Wei Y, Sun F (2018) Microstructures and mechanical properties of $\mathrm{Al} / \mathrm{Fe}$ and $\mathrm{Cu} / \mathrm{Fe}$ joints by continuous drive friction welding. Advances in Materials Science and Engineering Journal 2018:2809356. https://doi.org/10.1155/2018/2809356

Yilbas BS, Sahin AZ (2014) Friction welding: thermal and metallurgical characteristics. Berlin: Springer-Verlag Berlin Heidelberg. 